\title{
Alternative Methods For Preheating Outdoor Ventilation Air
}

\author{
Romanska-Zapala A. ${ }^{* 1}$, M. Bomberg ${ }^{2, *}$, M. Dechnik ${ }^{3}$, M. Fedorczak-Cisak ${ }^{3}$ and M. Furtak ${ }^{3}$ \\ 1 D. Eng., Małopolska Lab. of Energy Efficient Building (MLBE), and Automation and Information \\ Technologies, Cracow University of Technology, Cracow, Poland \\ 2 D. Sc. (Eng). Tech. D., Clarkson U., Potsdam, NY, USA, \\ 3 Małopolska Lab of Energy Efficient Building (MLBE), Cracow University of Technology, Cracow, Poland \\ * Correspondence: mark.bomberg@gmail.com, a.romanska@pk.edu.pl
}

\begin{abstract}
Growing popularity of smart and integrated buildings requires a review of methods to optimize the preheat of ventilation air. An integrated system permits using heat exchangers located in the mechanical room or in the future even using an exterior wall as a heat exchanger. One may ask the question how does the earth-air heat exchanger (EAHX) technology fitts into this function. EAHX has many advantages but also has many unaswered questions. Some of the drawbacks are: a possible entry of radon gas, high humidity in the shoulder seasons as well as the need for two different air intake sources with a choice that depends on the actual weather conditions. While in winter, the EAHX may be used continuously to ensure thermal comfort, in other seasons, its operation must be automatically controlled. To generate the missing information about the EAHX technology we reviewed literature and examined two nearly identical EAHX systems, placed either in ground next to the building or under the basement slab. Effectively, the information provided in this paper, shows advantages of merging both these approaches while the EAHX shoud be placed under the house or near the basement foundation.
\end{abstract}

Keywords: earth-air heat exchanger; energy efficiency; using thermal mass; smart and integrated control systems, thermal comfort

\section{Introduction}

As fraction of smart buildings in the market steadily grows, the integration of some sub-systems may change the economics of the tradtional solutions. In this paper, we are focused on pre-heating of the outdoor ventilation air and specifically on design and performance of the Earth Air Heat Exchnger (EAHX). Recent information on the need of two different air intake sources [1] and automatic control systems [2], changed the economics and warrant a broader review of EHX technology.

Conversely, in these instances when unfavorable soil conditons or risk of radon gas exists, or when hydronic heating system is used, the pre-heat of ventialtion air be located on the return of heating water $[3,4]$. To facilitate discussion on choices for pre-heat air, we decided to examine construction and performance of two similar EAHX systems: one in ground and the other placed under the basement slab.

\section{Literature review}

It is now a standard practice to heat or cool the fresh air between the point of intake and the entry to the mechanical room [5]. This can be done with earth-air heat exchanger (EAHX) [6]. The use of earth for cooling air was already known in historic Greece and Persia [8, 9], yet, recently it became popular for a different reason, namely for the energy conservation.

A number of publications on this topic exist; Pfafferot [10] or Szymanski and Wojtkowiak [6] who analyzed one year of EAHX performance, Żukowski [8] discussed different applications and 
Peretti et al. [8] analyzed design and evaluation of earth-to-air heat exchangers and Gan [11] focused on dynamic interactions between EAHX and the environment.

Recent publications deal with the efficiency of EAHX based on laboratory work[12] and CFD calculations [13]. Finally, two recent papers review various studies Kaushal [14] and life-cycle analysis of EAHX in a developing country by Uddin and Masudur [15]. Peretti et al. [8] and Kauhsal [14] focused on heat flow and Gan [11] on interaction with surrounding soil and Zukowski [7], Szymanski and Wojtkowiak [6] deal with possible applications, benefits and risk of poor design, few papers deal with evaluation of EAHX for annual cycles of field performance. Pfeffarot, [10] who examined three cases in Germany and Kaushal [14] who examined a case in Bangladesh and FlagaMaryanczyk et al. [16] as well as Skotnica and Wesolowski [12] in Poland. These publications highlight potential for reduction of energy needed for heating supply air in winter or cooling in summer but do not provide any guidance for integration of EAHX with other subsystems in the building.

\section{Experimental set-up}

The experimental set-up used in this research project, includes a direct intake of outdoor air though a wall and two remote intakes, both placed next to each other. One EAHX system was placed under the building and had the pipe slope ascending with drainge down pipe in $3 / 4$ distance to the mechanical room, while the other was placed outside the building and had the slope descenting with the drainage down pipe in the middle of the length.

Each EAHX is provided with temperature and humidity sensors connected to the data-logger. Measurements of earth temperatures are performed in two ranges (a) $-25^{\circ} \mathrm{C}$ to $0^{\circ} \mathrm{C}$ with precision of $\pm 0.3^{\circ} \mathrm{C}$ and (b) from $0^{\circ} \mathrm{C}$ to $40^{\circ} \mathrm{C}$ with precision of $\pm 0.1^{\circ} \mathrm{C}$. Relative humidity is measured in the range $10 \%-90 \%$ with precison of $\pm 3 \%$. Measuremnts are recorded every 5 minutes. One of these ground heat exchangers is located under the building (EAHX 1) and the other outside the building (EAHX 2, see the schematic shown in Figure 1).

The symols used in this Figure: $V_{1}, V_{2}, V_{3}-$ are the air valves with actuators, $\mathrm{T}_{1 \mathrm{in}}, \mathrm{T}_{2 \text { in }}$ - are the air temperature sensors on inlets, $\mathrm{T}_{1 \text { out }}, \mathrm{T}_{2}$ out - the same on outlets, $\mathrm{AF}_{1}, \mathrm{AF}_{2}$ - air flow meters; air handling unit's elements: Fin - supply fan, Fout - exhaust fan, $\mathrm{R}$ - recuperator, $\mathrm{H}$ - water heater, $\mathrm{C}$ - water cooler.

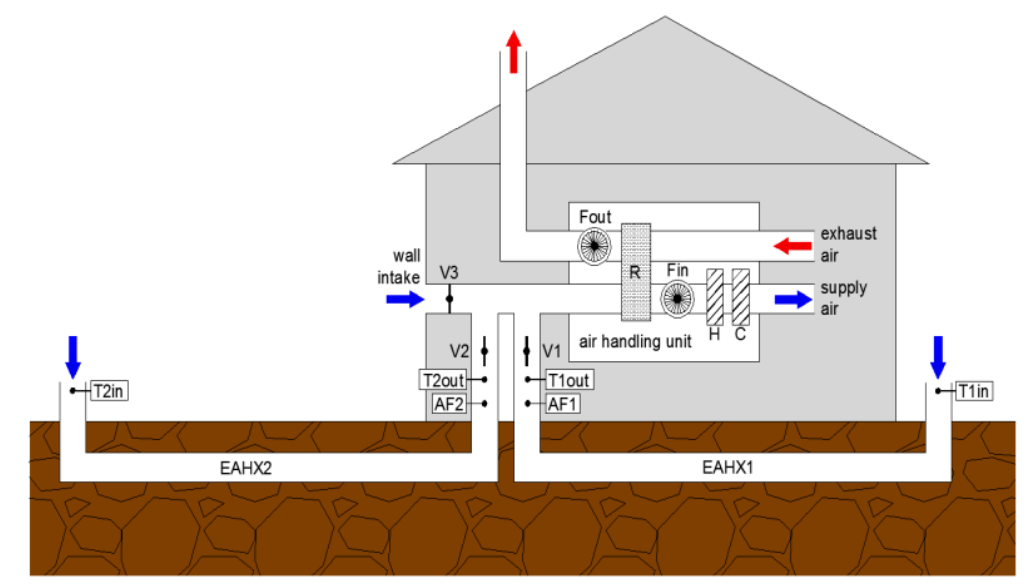

Figure 1. An experimental set-up with two ground air heat exchangers (EAHX) connected with the air handling unit. EAHX 1 is placed under the building, EAHX 2 the same system but placed outside the building. (From Romanska-Zapala [1]).

The mechanical room has rotational heat eachanger with $1850 \mathrm{~m}^{3} / \mathrm{h}$ flow and 80 percent efficiency, heating coil $3.25 \mathrm{~kW}$ and water cooling with $4.22 \mathrm{~kW}$ power. The experiments reported below were performed with air flow measured to be $400 \mathrm{~m}^{3} / \mathrm{h}$ on average and air speed in EHAX pipe with internal diameter of $185 \mathrm{~mm}$, about $4.1 \mathrm{~m} / \mathrm{s}$. Temperature was measured with 25 sensors 
within the system and 72 in the soil adjacent to the EAHX. The automatic steering and control system (BACS) was designed and built at the UniversityUniversity, based on the study "Assumptions and requirements for the measurement system; the architectural and construction design of the Małopolska Energy Efficient Building Laboratory. The heat exchangers were 60 and $59 \mathrm{~m}$ long of 200 $\mathrm{mm}$ diameter PVC pipe was either starting at a depth of $1.6 \mathrm{~m}$ with a downward $2 \%$ slope to a depth of $2.5 \mathrm{~m}$ or the opposite, starting at the depth of $2.5 \mathrm{~m}$ and ascending to $1.6 \mathrm{~m}$. Water drainage wells were installed in some distance from the end.

Both air inlets are on the North side of the building. An exhaust for air is located on the roof. As the selected technical charcteristics of EAHX represent a typical case allowing one to focus the analysis on efficiency of the EAHX solution and means of control and steering. The automatic control is necessary for the EQM technology as the exterior temperature changes combined with thermal mass of the building may cause more frequent switches between heating and cooling modes [19].

Figure 2 shows the lay-out of the pipes in both EAHX with temperature and humidity measurements made in one moment to highlight how instantaneous measuremnts may vary and where the vertical measurements of soil temperature were made. One may observe that both inlets and outlets of these two EAHX are placed next to each other and that measuremnts of soil temperatures will permit to see the effect of heat exchangers on the soil tempertureres.

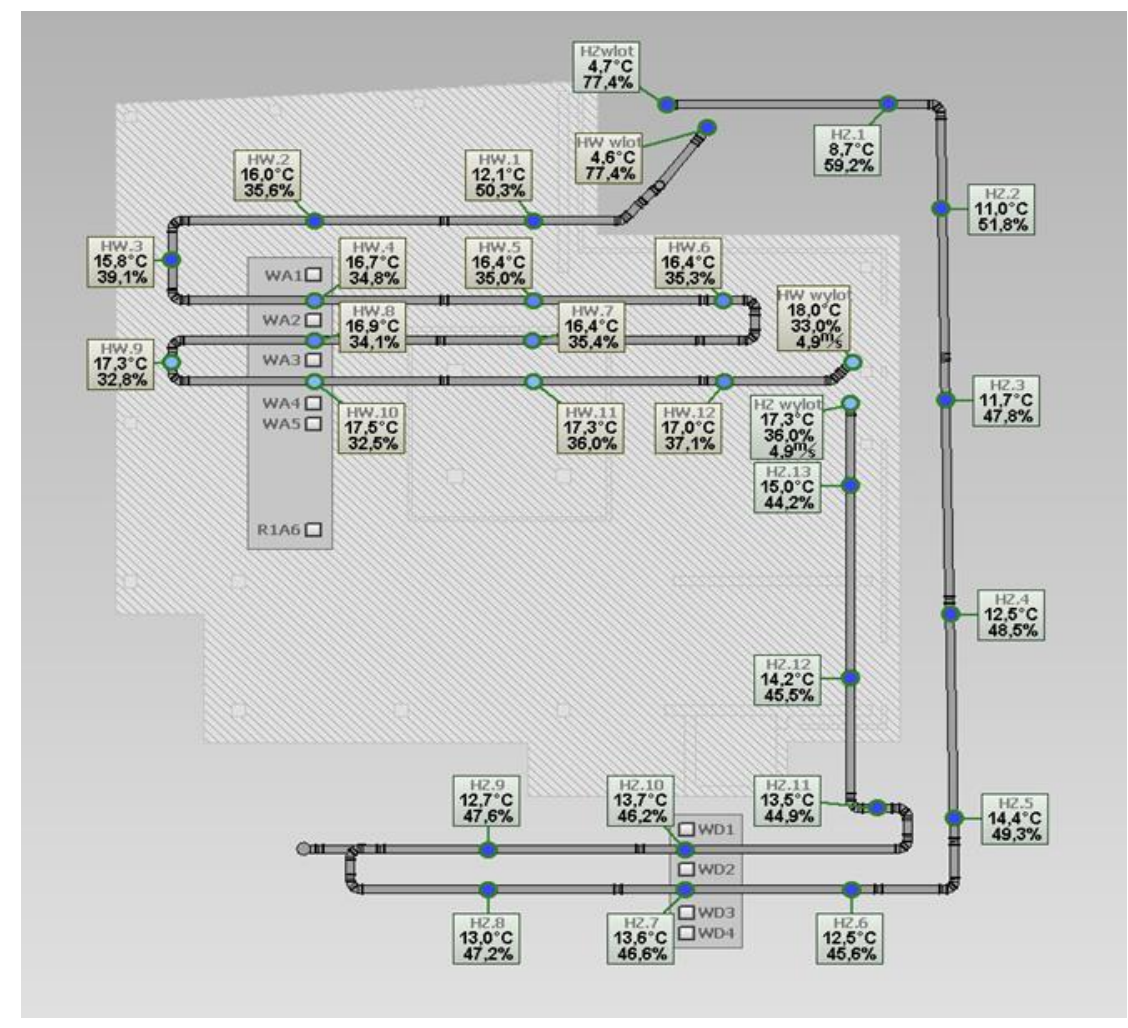

Figure 2. Schematic lay-out of both EAHX shown against the plan of the building. The temperature and relative humidity measuremnts in the EAHX pipes and their codes (HZ) are shown as well as vertical distribution of soil temperatures under the building (WA) and outside the building (WD). Temperature profile R1A6 is measured far from the heat exchangers and represent undisturbed soil temperature under the building.

\section{Reference temperature curves under insulated slab}

Figure $3 a$ shows a vertical cross-section through an insulated slab and Figure $3 b$ locations of vertical temperature measuring points vs the EAHX pipe as well as positions of the measurement points on the reference soil temperature line. 

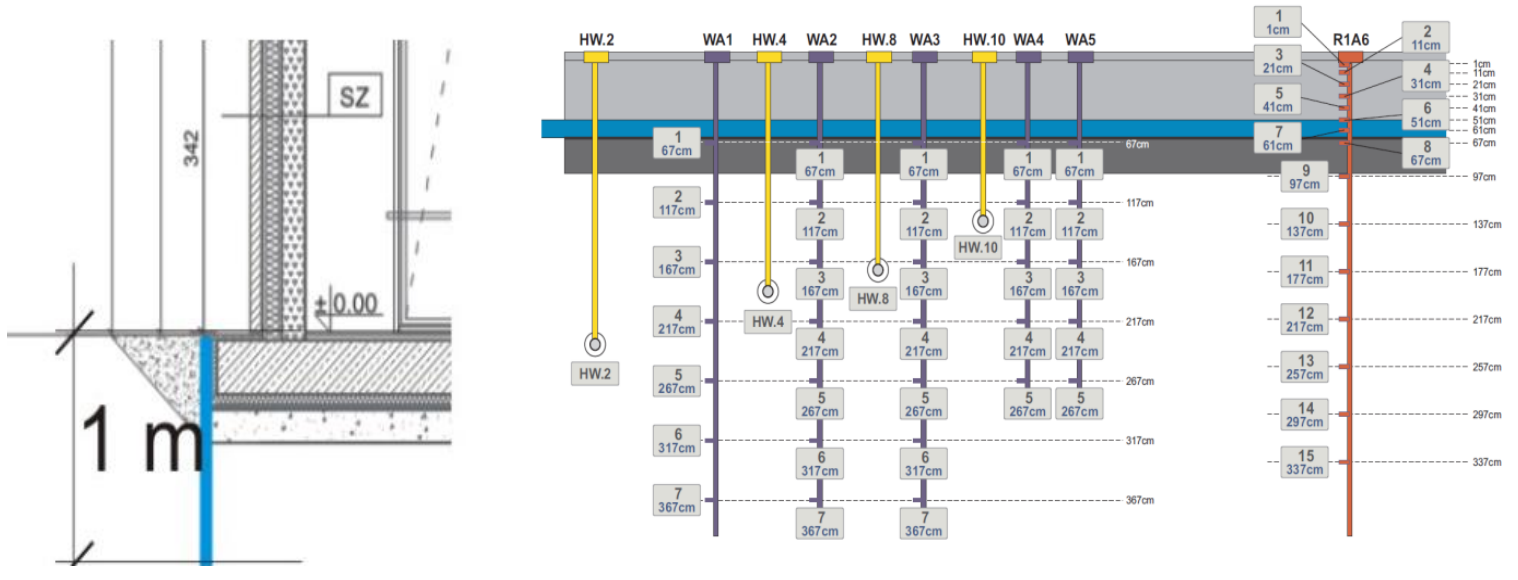

Figure 3a. Vertical cross-section through an insulated slab; Figure $3 b$ locations of vertical temperature measuring points vs the EAHX 1 pipes as well as positions of the measurement points on the reference soil temperature line.

The slab on ground has a total thickness $1020 \mathrm{~mm}$ and comprises of the following layers:

- Ceramic plates $30 \mathrm{~mm}$

- Concrete finishing layer $40 \mathrm{~mm}$

- Slab on ground with reinforced concrete $500 \mathrm{~mm}$ (placed on protective film covering)

- High density extruded polystyrene (XPS) $150 \mathrm{~mm}$ (placed on water resistant barrier)

- Light weight concrete - $300 \mathrm{~mm}$

Furthermore, to eliminate heat flow from the building to EHX2 placed in vicinity of the building one added a $1000 \mathrm{~mm}$ wide $150 \mathrm{~mm}$ vertical layer of the extruded polystyrene thermal insulation.

Figure 4: Schematic cross-section through tempertutre measurement for EAHX 1 and the reference soil temperature. Measurement points are located at dept of $10 \mathrm{~mm}, 510 \mathrm{~mm}$ (below concrete slab),

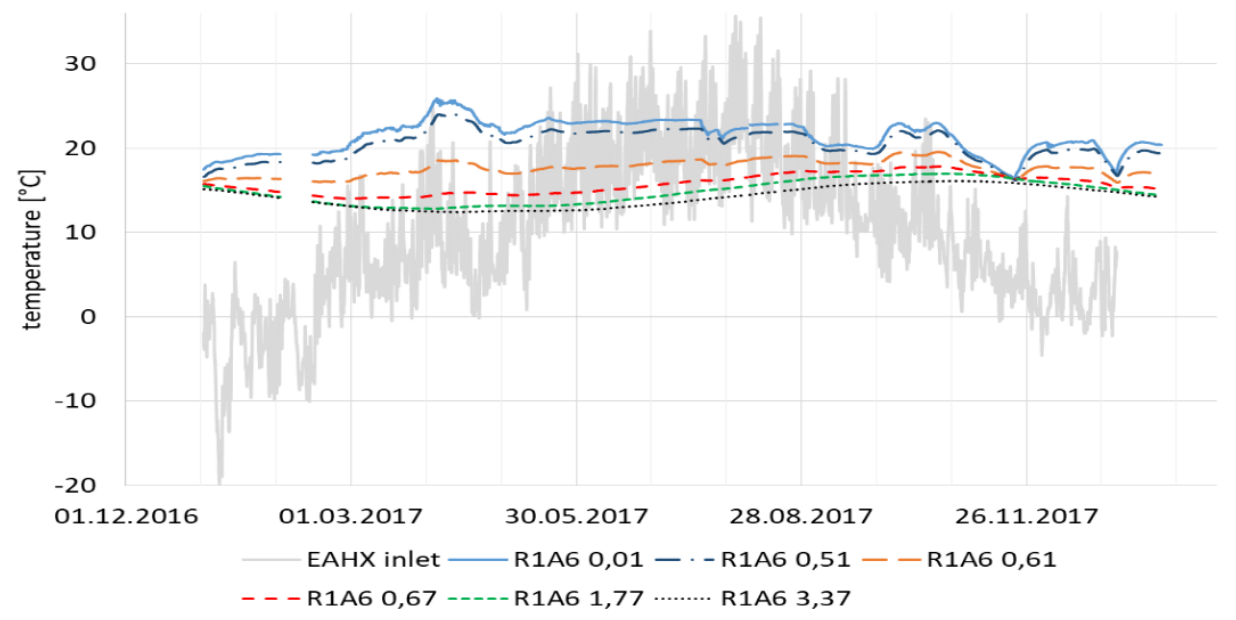

$610 \mathrm{~mm}, 670 \mathrm{~mm}$ (below thermal insulation) $1770 \mathrm{~mm}$ and the last at $3370 \mathrm{~mm}$

One can observe that $500 \mathrm{~mm}$ thick concrete layer modify the temperature but does not provide a smoth curve such as one obtained under $150 \mathrm{~mm}$ thick layer of a thermal insulation. The first meter of soil is assisting in a significant manner the provision of a stable and slowly varying temperature in summers, much lowet than the air temparture. Differences between the three lowest curves in 
Figure 4 are small indicating that any advantage of deeper placement of the EAHX pipe may not be justified by an increased cost of the deeper installation.

\section{Temperature in the EAHX pipe versus the reference curve}

Having established the reference temparture curves one may compare temperatures of the earthto-air heat exchanger (EAHX) with those in the soil on similar depth under the building. This is shown in Figure 5.
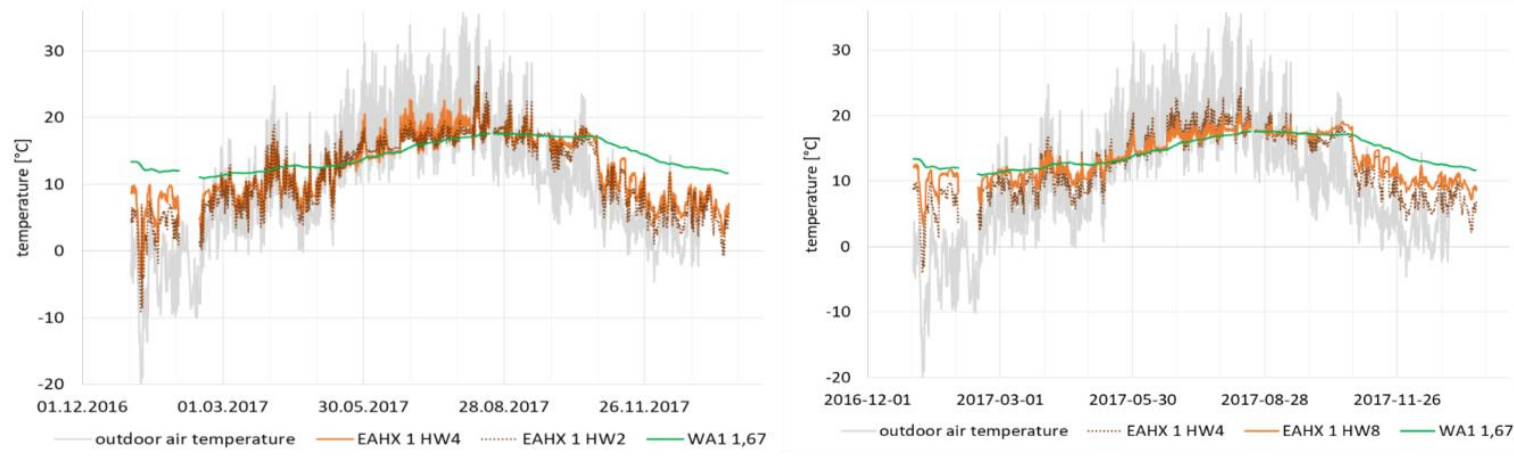

Figure 5. Tempartures in the beginning (left) and in the middle of the EAHX pipe (right) with the reference tempatures on two levels and air tempature (gray back ground).

Figure $5 \mathrm{~b}$ shows that tempartures in the middle of the EAHX are much closer to the soil reference level than in the beginning of the heat exhchanger pipe. Yet, all air tempatures in the EAHX pipe show oscilations, perhaps smaller than their temparture but still large enough to indicate that only a partial modification of air temperature took place. Yet, one often forgets that temparture field under the building varies in 3 dimensions, two of them being the distance from the edge of the building and the third a depth below the slab.

To highlight this point we show in Figure 5 the profile of temparture on similar depth but at a different distance from the building's edge.

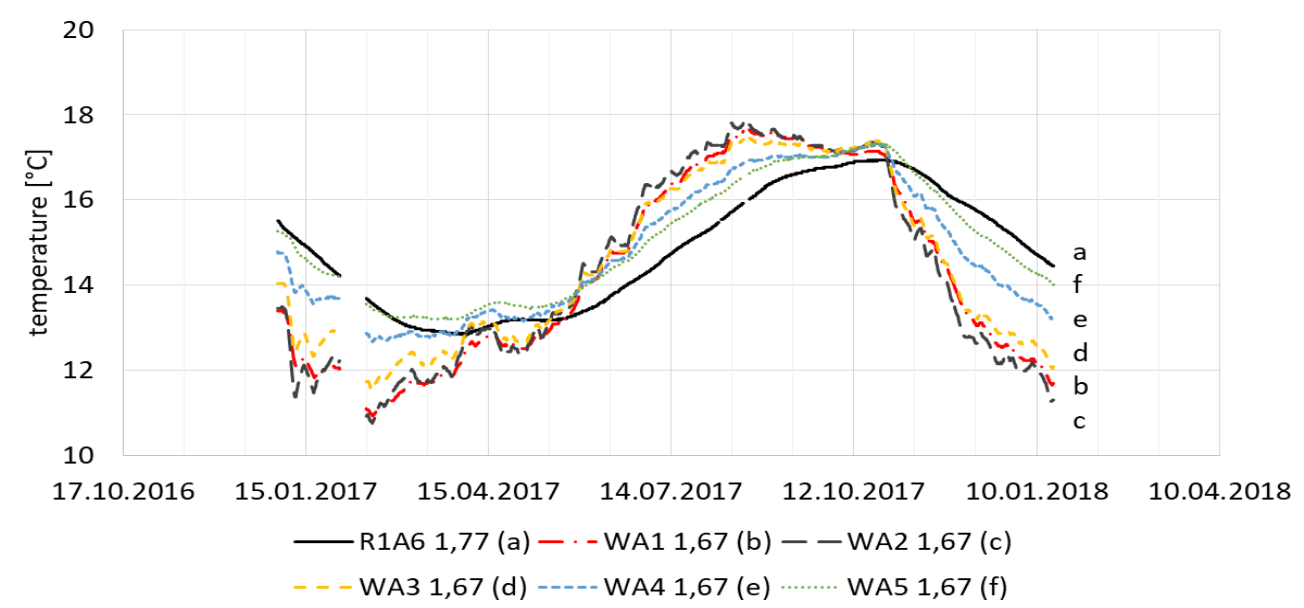

Figure 6. Measurements on the axix A (under the house) show the variation on the first three measurement profiles and coming closer to the reference temperature at some distance.

As Figure 6 show the temparture profile in the soil surrounding the EAHX pipes, we realize that there a multidirectional temperature field and a small but visible temperature change as a function of the distance from the building edge. Furthermore, temperature variations inside the EAHX pipes 
were reflected by the temperature of the soils and only at a certain distance (curve $f$ ) the effect of the EAHX pipe disappeared leaving the smooth curve of the soil temperturte changes. These factors must be taken into consideration when evaluating the optimum length of the EAHX pipe.

\section{EAHX length with multibranch pipe arrangement}

Amanowicz [17] analyzed EAHX with a few low diametr pipes finding the influence of geometrical parameters on the flow characteristics and on the total pressure losses in particular.

His sensitivity analysis considers variable number of parallel pipes, pipes length and main pipe diameter. He showed that the main pipes diameter that is $40 \%$ larger than are 1.4 the parallel pipes diameter can result in singnificant reduction of total pressure losses and improved airflow uniformity.

This was more important than branch-pipe length. Long pipes had 10 to 30 percent better uniformity in the air flow division but also 15 to 30\% higher resistance. These observations (experimental and CFD) are in a good agreement with our observations (Figure 7).

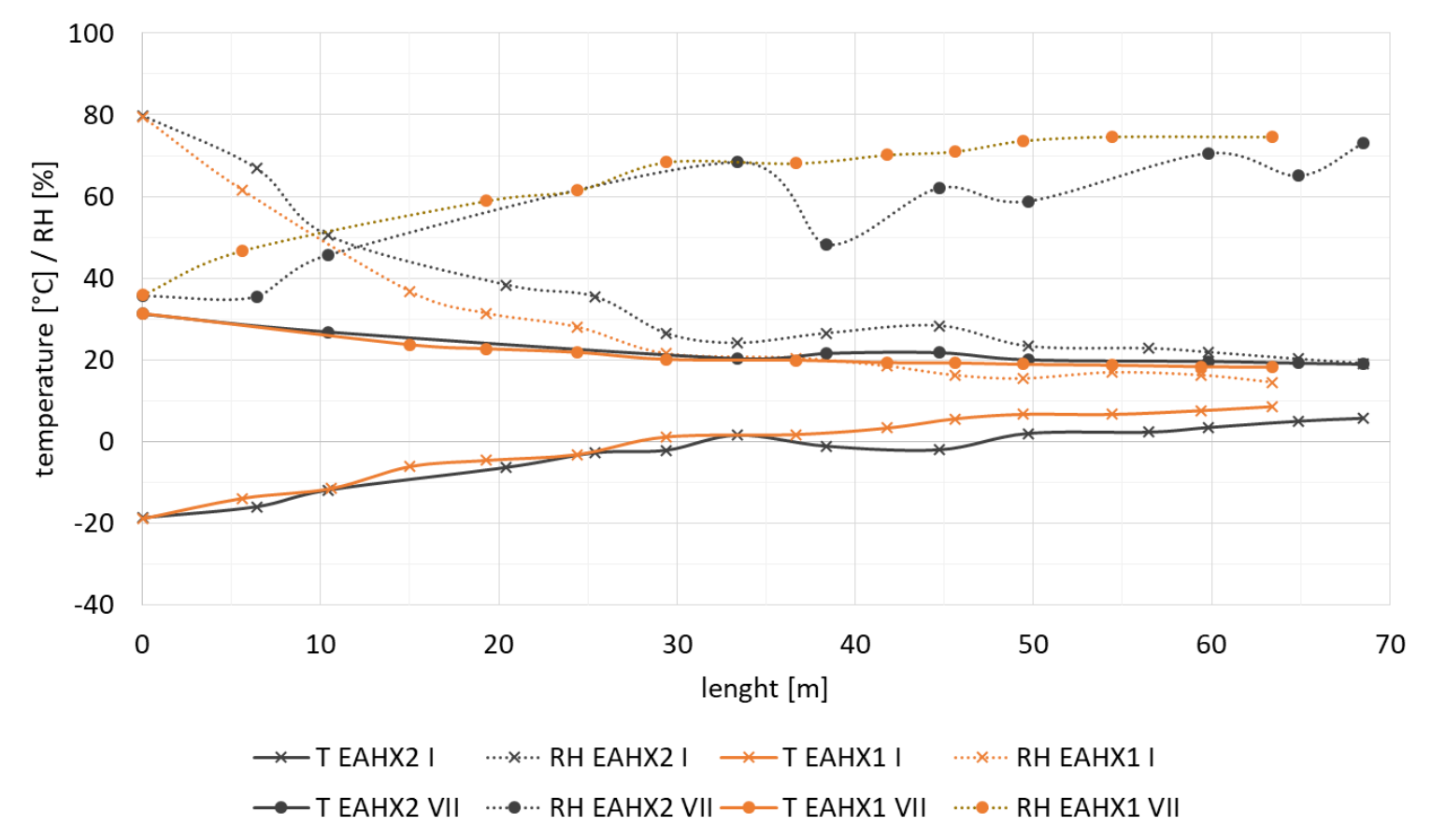

Figure 7. Effect of distance from the inlet measured every $5 \mathrm{~m}$ on temperature and relative humidity of air in the EAHX pipe at CUT. The graph shows these relations measured on July 20, 2017 (filled circles) and on January 7, 2017 and values for booth EAHX tested (marked with $\mathrm{x}$ ).

Figure 7 shows the whole length of the EAHX from ground level to the ground level so the virtual length of the underground path exceeds the $60 \mathrm{~m}$ of the actual heat exchanger pipe. This Figure explains some differences reported in the previous paper, namely the differences between measured values of temperature and relative humidity in the EAHX pipes. System 1, placed under the building has more uniform soil conditions that system 2 that is exposed to the exterior climate.

In summer, there appears to be no difference in the temperature measured by both heat exchangers that drops from the initial 30 to $20^{\circ} \mathrm{C}$ over the first $30 \mathrm{~m}$ of the path. Finally even though one may observe slow changes of temperature over the whole $60 \mathrm{~m}$ of the EAHX length the change on the first $30 \mathrm{~m}$ is much higher than on the second $30 \mathrm{~m}$. For both the summer and winter we get about $75-80$ change in the first $30 \mathrm{~m}$ distance. We may say that in the studied case the length of $30 \mathrm{~m}$ is sufficient for the design purposes. 
Yet this question cannot be answered without addressing the floor area that the studied case relate to. When considering the reduction of air speed to a typical $2 \mathrm{~m} / \mathrm{s}$ from the current $4.1 \mathrm{~m} / \mathrm{s}$ and for the current floor area of $423 \mathrm{~m}^{2}$ and using the air change rate of 0.35 ach (minimum for health purposes) for the room height of $2.7 \mathrm{~m}$ one obtains about $225 \mathrm{~m}^{2}$ floor area.

\section{Comparing performance of EAHX 1 with EAHX 2}

Figure 8 shows temperature and relative humidity in the outdoor air as well as in the two EAHX systems in one week of January 2017.

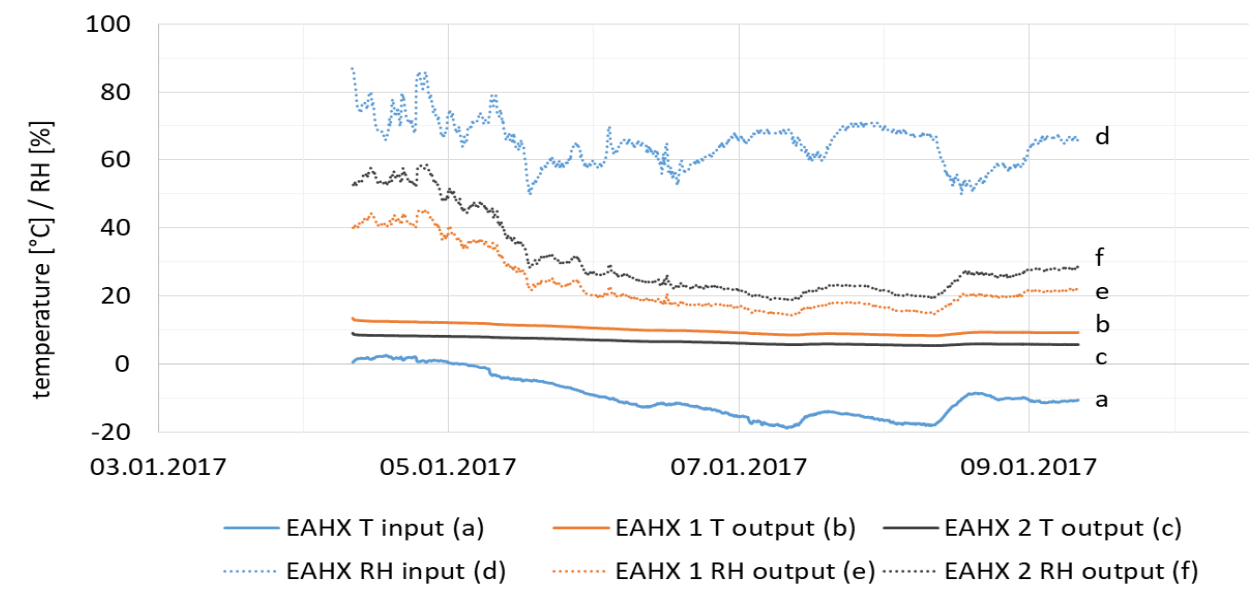

Figure 8. Temperature and relative humidity in the outodoor air (EAHX input, color: blue) as well as the output from the EAHX1 (color: orange) and EAHX2 (color: black) during five days in January 2017.

One may observe that with the outdoor temperature falling from near zero to minus $19{ }^{\circ} \mathrm{C}$, there is a slight decrease of the temperature in the EAHX pipes. The absolute humidity appears to be constant and relative humidity follows the temperature changes in the EAHX pipes. The temperature of the EAHX 1 that is under the building is a few degree higher in the winter.

\section{Calculating performance of the EAHX}

In this section we will calculate the ability to provide the heating or cooling energy by the EAHX 1 and 2 on the base of measured temparture and humidity and mean air velocity of the air coming and leaving the EAHX.

In these calculations $\varphi$ - is the relative humidity of air, $\mathrm{p}-$ atmospheric pressure of air [Pa], $\mathrm{x}-$ absolute humidity of air $[\mathrm{kg} / \mathrm{m} 3], \mathrm{T}$ - air temperature $\left[{ }^{\circ} \mathrm{C}\right]\left(\mathrm{T}_{\text {inlet }}\right.$ - on inlet to EAHX and Toutlet - on exit from EAHX), M- rate of the air mass flow $[\mathrm{kg} / \mathrm{s}]$, V- mean flux [m3/s] here 0,11111m3/s that corresponds to $400 \mathrm{~m} 3 / \mathrm{h}, \mathrm{I}$ - Enthalpy [kJ/kg] (Iinlet - on inlet to EAHX and Ioutlet - on exit from EAHX), P-power $[\mathrm{kW}]$ and the following equations were used:

$$
\begin{aligned}
& x=0,622\left(\left(\varphi p_{s}\right) /\left(p-\varphi p_{s}\right)\right), \text { where } \\
& p_{s}=611,2 e^{\wedge}\left(\left(17,58^{*} T\right) /\left(241,2^{*} T\right)\right) \\
& \mathrm{I}=1,0049 T+\left(2486,5+1,905 T-0,0016 T^{2}\right) x \\
& P=(\text { loutlet-linlet }) M,
\end{aligned}
$$$$
\text { Where: } M=V p /\left(287,05\left(\left(T_{\text {inlet }}+T_{\text {outlet }}\right) / 2+273,15\right)\right)
$$ 


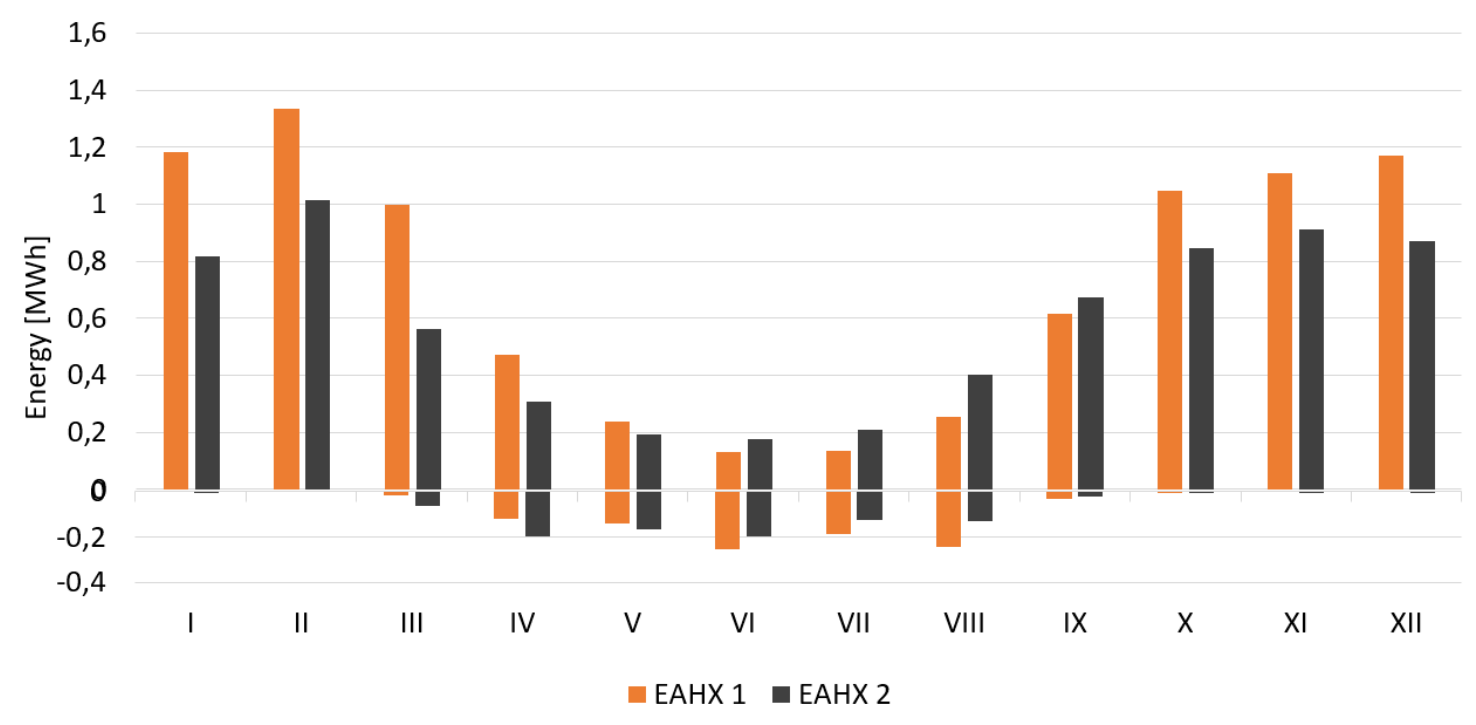

Figure 9. Monthly calculation of heating (+) and cooling (-) capability (indexes) of each of the tested EAHX.

Figure 9 shows the calulated capabilities of both EAHX 1 and 2 showing that EAHX 1 located under the building produced more heating energy in winter and cooling in summer than EAHX2 located in the the ground adjaced to the builidng. We have called it heating index because in months March through September we may observe that both heating and cooling capability should be used and as previously discussed by Romanska-Zapala [1] one needs to employ an automatic steering for either heating or cooling and selection of outdoor inlet or EAHX.

\section{Discussion on performance of EAXH1 and EAHX 2}

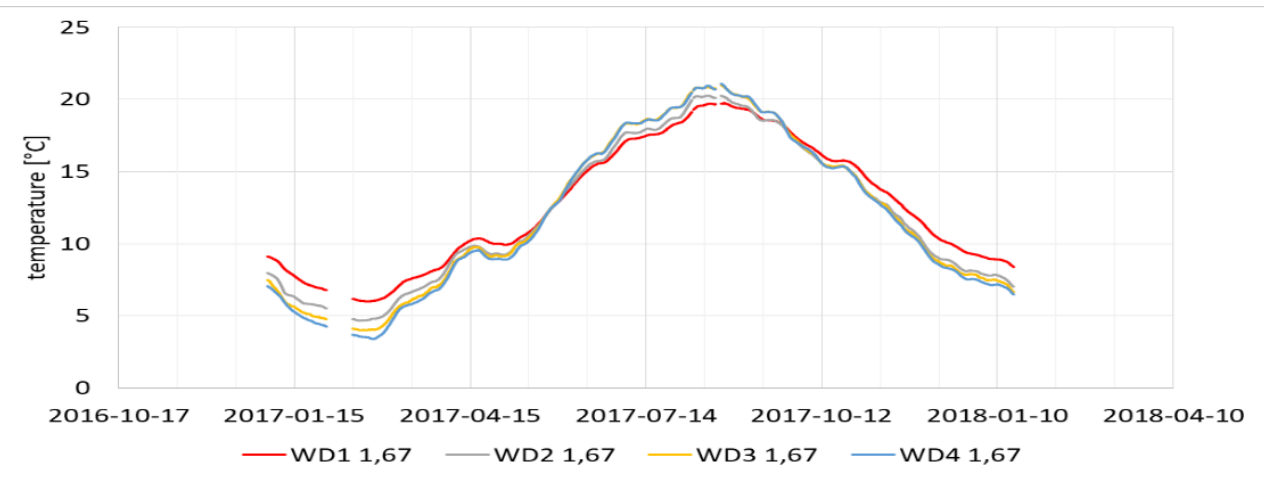

Figure 10. Measurements on the axix D (outside the house) show the smaller variation between different temperature profiles but much larger differences between winter and summer than measured on the axix A.

The above presented permit drawing a few conclusions. The exit temperature of both heat exchangers varied throughout the year. During the spring, temperature steadily increased reaching in the summer $17-19^{\circ} \mathrm{C}$, while in the autumn it decreased reaching in the winter $6-7{ }^{\circ} \mathrm{C}$. The differences in construction of two tested heat exchangers were small, namely two 45 degree connectors instead of two with 90 degree angles, ascending EAHX 1 versus descending EAHX 2, however, the difference in performance between persisted through all seasons. As EAHX system 1 
(located under the house) showed better performance than system 2, located outside the house one may conclude that the main reason was use of $150 \mathrm{~mm}$ thick high performance thermal insulation. Looking at the variation of performance between different parallel segments of the EHAX 1 pipes (under the house) one may also observe that they were located too close to each other.

Finally, one may observe that placing the EAHX under layer of thermal resistance of Rsi about $5\left(\mathrm{~m}^{2} \mathrm{k}\right) / \mathrm{W}$ or U-value $0.2 \mathrm{~K} /\left(\mathrm{m}^{2} \mathrm{~K}\right)$ is comparable with the effect of the deeper placement of the EAHX. This is shown in Figure 11 on temperature profiles measured in the axia D (open soil) on depth of 2.67 and $3.67 \mathrm{~m}$.

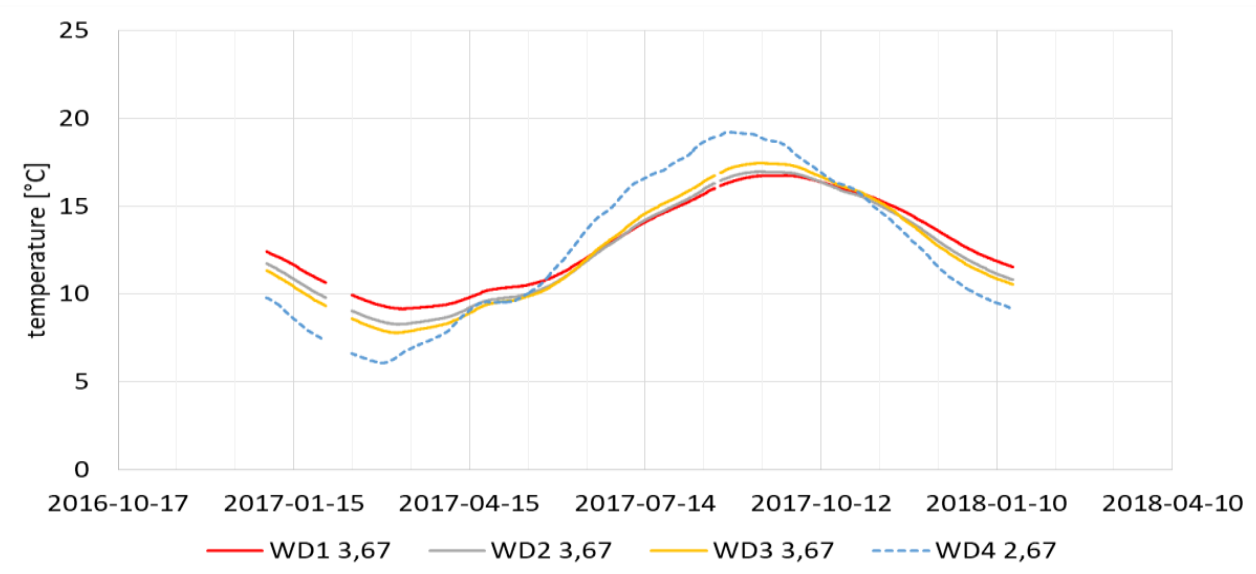

Figure 11. Temperature measured on the axix D outside the building.

One can observe in Figure 11 that deeper placement of the EAHX slightly increases the thermal lag and flattens the yearly temperature oscilation to the amplitude displayed by the EAHX 1, i.e., come closer to the optimal comfort conditions.

\section{Discussion on the EAHX technology}

If there is no soil gas (radon) an EAHX can be placed directly under insulated concrete slab place on ground or in the basement floor. Figure 8 shows that in winter temperature of air coming from the EAHX number 1 is significantly warmer than that from the EAHX number 2 . In a house, the air inlet can be located under the staircase of the entrance. Figures 10 and 11 show that the depth of $2 \mathrm{~m}$ or more is needed to fully benefit from EAHX placed in ground, yet the same performance was achieved with $0.7 \mathrm{~m}$ depth under the basement of the building (Figures 4 and 5). If EAHX is placed under the building it should be located as much as possible in the central area of the basement slab. Effect of the distance from the building edge was shown in Figure 6.

So, if placement under the building is not possible, placement next to the drainage pipe at the foundation is the preferred location. In the latter case, a traditional practice of insulating the basement wall on the first $60 \mathrm{~cm}$ below ground and than placing a $1.2 \mathrm{~m}$ strip of $50 \mathrm{~mm}$ thick, extruded polystyrene almost horizontally i..e with a slope of $2-3$ percent. (Any water resistant foam with a similar U-value can be used instead of polystyrene)

The length of the EAHX pipe should be at least $25-30 \mathrm{~m}$. Figure 7 support literature findings [17] and shows that $30 \mathrm{~m}$ length provided a sufficient reduction of air temperature variation. The length of EAHX may further be shortened if one uses wide collecting pipe with two to four much smaller branches. For instance in NY demonstration house [18] we had $3 \mathrm{~m}$ pipe with $100 \mathrm{~mm}$ diamneter with two 45 degree dividers collecting four $10 \mathrm{~m}$ long with diameter $25 \mathrm{~mm}$ PVC pipes placed $200 \mathrm{~mm}$ apart.

In another NY project $[3,4]$ where no drainage was needed on 3 sides of building that was located on a slope, the underground pipe was short and the bulk of the pre-heat was achieved on an interior het exchanger buit on return from the hydronic heating. This type of solution can also be used in 
retrofitting buildings where there are no basements or water problems in the existing basements. In case of water seepage through the basement wall, one must excavate soil next to the building and provide exterior thermal insulation with drainge [19] and of course either water or air heat exchanger.

Use of EAHX have an obvious appeal: they can provide reduce the energy needed for air conditioning and increase the feeling of comfort. Yet Yet the EAHX must be ue used together with an air bypass that takes air directly from the outside. Having a choice between two sources of a fresh air requires a control system. The most unsophisticated system for a small house may comprise of a differential temperature sensor with a motorized valve can controls the mixing of air coming from two sources. This valve should also have a manual override. The next devices in the mechanical room are dehumiditier and dust particle removal. This will improve air quality.

Figure 9 shows that during 6 months for EAHX 1 and 8 moths for EHAX 2 one needs both heating and cooling. That indicates the need for switching between the two air sources. As power available from the EAHX1 in Figure 9 is caluated pe hour, it implies that is varies from $4 \mathrm{~kW}$ to zero, while the fan operation took $75 \mathrm{~W}$, so the control system must include two elemnets: (a) fraction of time when fresh air is delivered, and (b) the mixing ratio between air delivered from the EAHX and air delivered from the direct air intake. One must remember that the ventialtion air is added to the unplanned air flow (UAF or air infiltration ratio) an this means that in ideal case the UAF is experimentally determined for specific builing.

Elsewhere [20], we have discussed what criterion of air-tghtness should be set to permit significant role of natural (uncontrolled) air infiltration to the building. This obviously will decide upon the setting of the criteria for (a) and (b) as much as cost of installation and operation versus potential to save electrical energy. One should also remember that using EAHX in cold climates, requires equipment that does freeze up in the winter and cost of mainatance, and in particular that air filters typically need cleaning or replacing every $6-12$ months.

On the advantage side of EAHX technology is the capability to increase the amount of ventilation air during the periods when the temperature of the outdoor air is within a few degrees of the desired room temparture. Experience form the state of California indicates that over-venetilation of dwellings with outdoor air has multiple positive effects: it replaces a night cleaning of the dwellings, improves their feeling of thermal comfort and reduces the need to open windows when the weather is not suitable for it. As in integrated hydronic heating or cooling systems always comes with a water buffer tank, placing an air coil in each of them for some pre- conditioning intake air permits to broaden the range of air tempretures in which the occupant may use the over-ventialtion feature.

Finally, there is another consideration with importance related to the size of the builing, namely the complexity of the ventialtion system. While making a central mechanical ventilation with a controlled supply and uncontrolled exhaust is easy for a small building, it is not easy for multi-story residential building [21]. The next section of this paper expands on pre-heat of the ventialtion air for the future buildings.

\section{A look into the future}

The future technology will deal with a building that collaborates with the smart grid in which one of the critical subsystems is the hybrid ventilation, i.e., that included both mechanical or natural ventilation. In past, over-pressurizing the indoor air was not allowed because of the risk of water vapor condensation when air is carried into the building enclosure. Yet, as the current low energy buildings can be designed with an adequate control of air flow in walls, an unbalance of indoor and outdoor pressures can easily be tolerated. So, looking from the building physics point of view, one may use an indoor air overpressure in summer and under-pressure in winter because in both cases the air transport goes from lower concentration of water vapor towards the higher one.

Such a design has two completely different air flow patterns. In summer, one takes the warm and humid outdoor air, cools it in a mechanical heat exchanger, dehumidify and remove dust particles before it enters to the air handling unit delivering air with positive pressure. The clean supply is delivered to the house of each dwelling in a multi-unit building by a valve with controlled 
flow rate under specified e.g., 10 Pa over-pressure. The overpressure created by a programable ventilator in the air handler will result in natural exhaust ventilation through bathroom and kitchen ventilation openings and through the individual ventilation system that will be provided in the exterior walls of the solar exposed rooms. The water vapor retarder is also used to reduce moisture ingress from the interior. These ventilation cavities are also used for individual ventilation that works automatically under night ventilation scheme, and may also be operated manually.

In winter, the warm air is removed through exterior (drainable) cavities that would also act as the energy exchangers. Yet for this system to provide an effective humidity control in summer one needs a layer of capillary active material that would provide a moisture buffering capability. Such materials are being developed now.

\section{Concluding remarks}

Originally, in Europe, the EAHX was considered a separate element of the design that could be added to the passive house approach. In America, the concept of EAHX could not compete with already established use air conditioning. Thus, this research was designed to fill information into the gaps in EAHX design. Yet, while performing this research, we noticed a dramatic increase of popularity of modern hydronic systems, there was a reason to review the role of ventilation [20]. On the other hand, in the cold climate analysis, the role of the coupling between the house and earth was dramatically increased when the cluster design replaced the analysis of a single, energy efficient house. In effect, the value of the above presented research became high again because it highlights a new component of the integrated approach, namely the computer based informatics.

Computer-based informatics has recently joined the building science to respond jointly with to the need of holistic evaluation of building energy performance. To realize how important is today the possible merger of these two disciplines, let us quite the requirements for students of the Electrical and Computer Engineering Departmento fo our Univerity:

- Knowledge of application of the mathematical methods in modeling, analysis and synthesis of the control and steering systems and in particular in automatics' algorithms and their optimization

- Knowledge of development trends and new achievements in automatics and in particular in the artificial intelligence for application to control and steering systems

- Knowledge of micro processing and programmed systems for measuring, control and steering as used in the electrotechnical applications

Automatics discussed in this work is applied to near zero energy housing, where one can optimize reduction of energy with integrated control and steering system while maintaining good indoor environment. Yet, the currently used technology of energy efficient buildings, called passive houses plus, i.e., passive measures with some contribution of solar gains, already came to the economic maturity, i.e., to the diminishing returns on increased investing.

As an example, we can take an advanced Canadian detached house that uses $70 \mathrm{kWh} /\left(\mathrm{m}^{2} \mathrm{a}\right)$ of total energy. Heating, cooling, ventilation and heting domestic water, all of them depending on climate, cover about 50 percent of the energy use and the house services and eneterainemnt, independent of the climate, cover the remaining 50 percent of energy. In effect, when one increases thermal insulation and airtightness of the building with 20 percent, the energy consumption is reduced by 10 percent, only. Prevailing technology of passive houses with a solar contribution, provides significant reduction of energy in warm climates but reached its economical limit in cold climates. 
A review of low energy buildings $[1,22]$ indicated that the constant indoor temperature eliminated any contribution of thermal mass to the energy balance. To restore the thermal mass contribution, we decided to integrate heating and cooling with the building structure and to use the adaptable climate approach for indoor spaces. This approach is discussed elsewhere [23]. Observe that system integration again increases the role of the modern building automatics.

We may conclude that the next generation of low energy buildings becomes a part of the fourth industrial revolution. The first one used the steam created by a process of burning coal, the second brought us automobiles propelled by the gasoline, the third brought us electricity generated in energy centers and the current industrial revolution is merging decentralized sources of energy with information technology. In this process the buildings are not only generating energy but also storing it. This is a development specific to the cold climates where each building alone cannot reach zero energy level, yet a cluster of buildings in combination with ground energy storage and solar radiation may give us zero energy status.

Author Contributions: Formal analysis was performed by Anna Romanska-Zapala and Mark Bomberg; Funding acquisition: Malgorzata Fedorczak-Cisak and Marcin Furtak; Investigation: Miroslaw Dechnik and Malgorzata Fedorczak-Cisak; Methodology: Mark Bomberg; Resources, Marcin Furtak; Software: Miroslaw Dechnik; Supervision, Anna Romanska-Zapala; Visualization, Miroslaw Dechnik; Writing draft and the sumission copy, Mark Bomberg.

\section{REFERENCES}

1. Romańska-Zapała, A., M. Bomberg, M. Fedorczak-Cisak, M. Furtak, D. Yarbrough, M. Dechnik, , Buildings with environmental quality management (EQM), Part 2: Integration of hydronic heating/cooling with thermal mass, Journal of Building Physics, 2018, 41(5), p.397-41

2. Dechnik,M., S. Moskwa, Smart House - intelligent building - the idea of the future (in Polish), Przeglad Elektrotechniczny, 2017, vol. 9, p. 1-10.

3. High Environmental Performance (HEP) - residential housing for NY state, Mark Bomberg, Terry Brennan, Hugh Henderson, Kevin Stack, Adam Wallburger, Jianshun Zhang, A final report to NY State Energy Research and Development Agency And National Center of Energy Management and Building Technology Submitted on April 15, 2009 and revised on July 15

4. Quality assurance and commissioning process in High Environmental Performance (HEP) house in NY state, T. Brennan, M. Bomberg, H. Henderson, K. Stack www.thebestconference.org/best1

5. Romańska-Zapała, A., M. Furtak, M. Fedorczak-Cisak, M. Dechnik, The Need for Automatic Bypass Control to Improve the Energy Efficiency of a Building Through the Cooperation of a Horizontal Ground Heat Exchanger with a Ventilation Unit During Transitional Seasons: A Case Study", WMCAUS 2018, Prague IOP Conference Series: Materials Science and Engineering, vol. 246

6. Szymański M., Wojtkowiak J., 2008, Analiza całorocznej pracy rurowego gruntowego wymiennika ciepła RGWC w układzie wentylacji mechanicznej budynku mieszkalnego, Ciepłownictwo, ogrzewnictwo, wentylacja, no 11/2008, p. 36-38

7. Żukowski, M., Assessment of Potential Applicability of Ground Air Heat Exchanger in Białystok" (in Polish), Ciepłownictwo, ogrzewnictwo, wentylacja, 2012, no. 8, p. 323-346.

8. Peretti, C., A. Zarrella, M. De Carli, R. Zecchin, The design and environmental evaluation of earth-to-air heat exchangers, A literature review, Renewable and Sustainable Energy Reviews, 2013, vol. 28, p107-116

9. Ionescu, C., T. Baracu , G-Elena Vlad , H. Necula , A. Badea,2015, “The historical evolution of the energy efficient buildings", Renewable and Sustainable Energy Reviews 49, pp. 243

10. Pfafferott, J, 2003, "Evaluation of earth-to-air heat exchangers with a standardised method to calculate energy efficiency", Energy and Buildings 35(10) p. 971

11. Gan, G. Dynamic interactions between the ground heat exchanger and environments in earth-air tunnel ventilation of buildings", Energy and Buildings, 2014, vol. 85, p. 12-22,.

12. Skotnicka-Siepsiak, A. M. Wesołowski, 2016, “Wydajność rurowego gruntowego powietrznego 
wymiennika ciepła w świetle laboratoryjnych danych pomiarowych w okresie zimowym", Ciepłownictwo, ogrzewnictwo, wentylacja, p. 71-75, 47/2 .

13. Congedo, P.M., C. Lorusso, M. Grazia De Giorgi, R. Marti, D. D’Agostino,2016, “Horizontal Air-Ground Heat Exchanger Performance and Humidity Simulation by Computational Fluid Dynamic Analysis", Energies 9(11), 930

14. Kaushal, M, 2017,“Geothermal cooling/heating using ground heat exchanger for various experimental and analytical studies: Comprehensive review", Energy and Buildings 139 p. 634

15. Uddin, M.S, A. Raju, R. Masudur, 2016, "Performance evaluation and life cycle analysis of earth to air heat exchanger in a developing country", Energy and Buildings, Volume 128, p 254,016.

16. Flaga-Maryanczyk, A., J. Schnotale, J. Radon, K. Was, 2014. “Experimental measurements and CFD simulation of a ground source heat exchanger operating at a cold climate for a passive house ventilation system", Energy and Buildings 68 (A) p. 562

17. Amanowicz Łukasz, Influence of geometrical parameters on the flow characteristics of multi-pipe earth-to-air heat exchangers - experimental and CFD investigations, Applied Energy, 2018, vol.226, Sept, 849-861

18. Lowell Lingo, Highlights from the Geo-Solar Test (GEST) house evaluation, Building Innovation Symposium, April 7, 2020, National Institut for Building Science, Washington, DC

19. Bomberg M, T. Kisilewicz and Ch. Mattock, Methods of Building Physics, 2017, Cracow Univ. Press, 1- 301,

20. Bomberg, Mark, Tomasz Kisilewicz and Katarzyna Nowak, Is there an optimum range of airtightness for a building?, J. Building Physis, 2016, 39(5), 395-421

21. Dudzik,M, K. Tomczyk, M. Sieja, Optimal dynamic error formula for charge output accelerometer obtained by the neural network, 2018 International Symposium on Electrical Machines (SME) : SME 2018, Andrychów, Poland, 10-13 June 2018 , IEEE 2018. doi: 10.1109/ISEM.2018.8442477. ISBN 978-153865210-7

22. Romanska-Zapala,Anna, Mark Bomberg and David Yarbrough Buildings with environmental quality management (EQM), part 4: A path to the future NZEB, J. Building Physis, 2018, 43(1), 3-21

23. Bomberg, Mark, David Yarbrough and Marcin Furtak Buildings with environmental quality management (EQM), part 1: Designing multifunctional construction materials, J. Building Physis, 2017, 41(3), $193-208$ 